\title{
Sputtering of beryllium oxide by deuterium at various temperatures simulated with molecular dynamics
}

\section{Hodille, Etienne}

2020-01-01

Hodille , E , Byggmästar , J , Safi , E \& Nordlund, K 2020 , ' Sputtering of beryllium oxide by deuterium at various temperatures simulated with molecular dynamics ', Physica Scripta, vol. T171, no. 1 , 014024 . https://doi.org/10.1088/1402-4896/ab43fa

http://hdl.handle.net/10138/327293

https://doi.org/10.1088/1402-4896/ab43fa

acceptedVersion

Downloaded from Helda, University of Helsinki institutional repository.

This is an electronic reprint of the original article.

This reprint may differ from the original in pagination and typographic detail.

Please cite the original version. 
Preprint of article accepted for publication in Physica Scripta

\title{
Sputtering of beryllium oxide by deuterium at different temperatures simulated with molecular dynamics
}

\author{
E A Hodille, J Byggmästar, E Safi, K Nordlund \\ Department of Physics, University of Helsinki, P. O. Box 43, FI-00014,Finland \\ E-mail: etienne.hodille@helsinki.fi
}

\begin{abstract}
The sputtering yield of beryllium oxide (BeO) by incident deuterium (D) ions, for energies from $10 \mathrm{eV}$ to $200 \mathrm{eV}$, has been calculated for temperatures between $300 \mathrm{~K}$ and $800 \mathrm{~K}$ using classical molecular dynamics. First, cumulative irradiations are done to build up a concentration of $\mathrm{D}$ in the material, equal to the one experimentally measured, that varies from 0.12 atomic fraction $(300 \mathrm{~K}$ $500 \mathrm{~K})$ to 0.02 atomic fraction $(800 \mathrm{~K})$. After building up the concentration of $\mathrm{D}$, non-cumulative irradiations are done to estimate the sputtering yields of $\mathrm{BeO}$. For all incident energies, the sputtering yield peaks at $500 \mathrm{~K}$, being closely related to the decrease of the concentration of $\mathrm{D}$ above this temperature. While for 10 $\mathrm{eV}$, the concentration of $\mathrm{D}$ on the surface drives the temperature dependence, above $30 \mathrm{eV}$, it is the amount of surface damage created during the cumulative irradiation.
\end{abstract}

Keywords: Plasma-wall interactions, Molecular dynamics, Beryllium oxide, Deuterium 


\section{Introduction}

Beryllium (Be) is the chosen material for the first wall of JET [1, 2] and ITER [3]. Ions coming from the plasma can lead to sputtering of this material, reducing the life time of the plasma-facing components and creating a source of impurity for the plasma. In addition, the sputtered material can migrate in the edge plasma and be redeposited on surfaces creating a deposited layer that is expected to be the main media for fuel retention in ITER 4, 5. It is thus important to estimate the sputtering of Be materials in a fusion environment.

Be oxidises easily, and a thin Beryllium oxide $(\mathrm{BeO})$ layer can be formed with a small pressure of oxygen. Thus, BeO layers can be formed between plasmas and quickly removed in strong sputtering area during plasma operation (in limiter plasma for instance). $\quad \mathrm{BeO}$ can also be formed during offnormal events like melting of $\mathrm{Be}$, as $\mathrm{BeO}$ inclusions have been observed by Raman spectroscopy in melted regions [6, 7]. The sputtering of $\mathrm{BeO}$ by deuterium (D) ions is thus of importance for the description and understanding of the plasma-wall interactions.

In this work, we use molecular dynamics (MD) to estimate the sputtering yields of $\mathrm{BeO}$ by $\mathrm{D}$ ions. In a previous study, MD has been used to determine these sputtering yields at $300 \mathrm{~K}$ [8]. During tokamak operations, the temperature of the first wall can rise above $300 \mathrm{~K}$. Here, the MD simulations have been extended to provide estimations of sputtering yields of $\mathrm{BeO}$ up to $800 \mathrm{~K}$.

\section{Method}

The irradiation of $\mathrm{BeO}$ was simulated with classical MD using the MD code PARCAS [9]. The simulation cells contain three species: beryllium (Be), oxygen (O) and Deuterium (D). To describe the interactions between these species, Tersoff-like potentials [10, 11 have been used. For these interactions, D atoms are considered as $\mathrm{H}$ atoms with a mass of 2.014 atomic mass units. The Be-Be and Be-H potential are both taken from 12 (version II), the $\mathrm{H}-\mathrm{H}$ potential is taken from [13], the $\mathrm{O}-\mathrm{O}$ is taken from [14], the $\mathrm{Be}-\mathrm{O}$ is taken from [15] and the $\mathrm{O}-\mathrm{H}$ part is taken from [8]. The full Be-O-H potential was previously shown to give good agreement between simulated and experimental sputtering yields [8, and is therefore well-suited for plasma- wall interaction simulations.

In [8], it is shown that the sputtering yield increases with $c_{\mathrm{D}}$ in the material. The best comparison between MD and experimental sputtering yields is obtained at $300 \mathrm{~K}$ for $c_{\mathrm{D}} \approx 0.12$ atomic fraction (at.fr.) which is the saturation concentration of deuterium in $\mathrm{BeO}$ determined experimentally for irradiation at 300 $\mathrm{K}$ [16. Thus, for the present simulations at different temperatures, the temperature dependent values of $c_{\mathrm{D}}$ in $\mathrm{BeO}$ are also used. Roth et al [17] as well as Alimov et al [18, reports those values of $c_{\mathrm{D}}$ for temperatures between $300 \mathrm{~K}$ and $773 \mathrm{~K}$. They are shown on figure 1 . Both experimental studies agree on the evolution of $c_{\mathrm{D}}$ in $\mathrm{BeO}$ with temperatures: $c_{\mathrm{D}}$ is about constant (equal to 0.12 at.fr.) from $300 \mathrm{~K}$ to $500 \mathrm{~K}$ and it drops above $500 \mathrm{~K}$.

The simulation set-up used in this paper is the

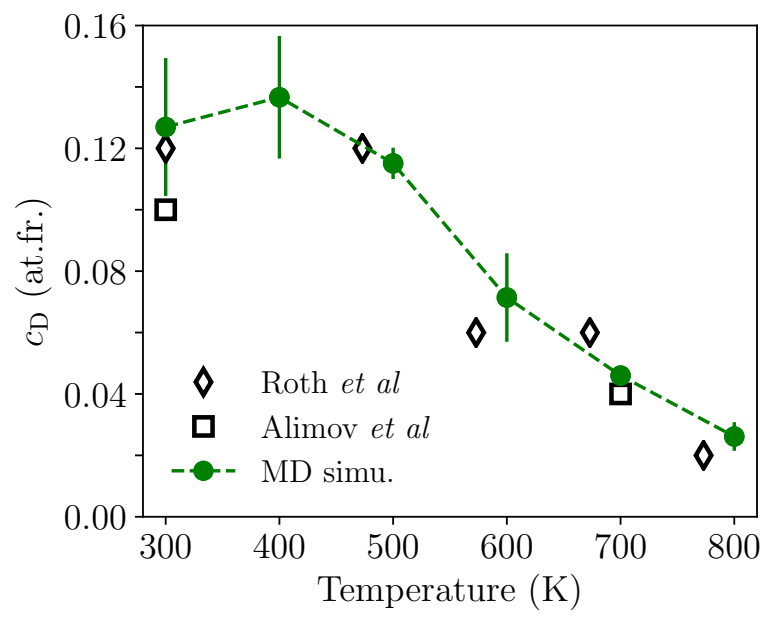

Figure 1: Evolution of the deuterium concentration, $c_{\mathrm{D}}$, with temperatures. The open symbol are the experimental values reported by Roth et al [17] and Alimov et al [18] (experiments). The closed circles are the value of the deuterium concentration, $c_{\mathrm{D}}$, used in the MD simulations (averaged on all 6 energies used in this paper). The error bars are the standard deviation over all 6 energies.

same as in 8 : a wurtzite $\mathrm{BeO}$ cell with a $(000 \overline{1})$ surface is irradiated with ion energies of $10 \mathrm{eV}, 30 \mathrm{eV}, 50$ $\mathrm{eV}, 80 \mathrm{eV}, 140 \mathrm{eV}$ and $200 \mathrm{eV}$. The irradiated temperatures are $400 \mathrm{~K}, 500 \mathrm{~K}, 600 \mathrm{~K}, 700 \mathrm{~K}$ and $800 \mathrm{~K}$. The sputtering data at $300 \mathrm{~K}$ are taken from [8] and have 
- o.

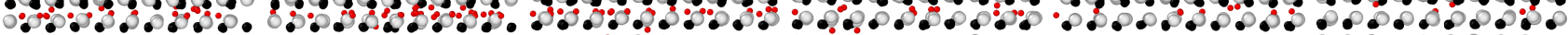

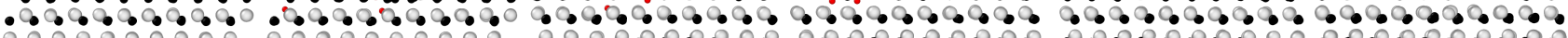

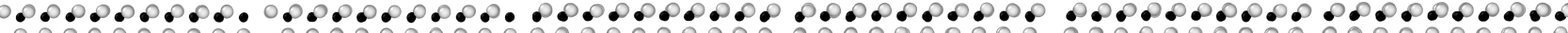

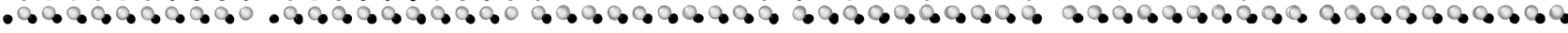
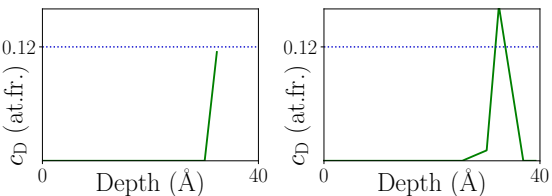

(a) $10 \mathrm{eV}-300 \mathrm{~K}$

(b) $10 \mathrm{eV}-400 \mathrm{~K}$

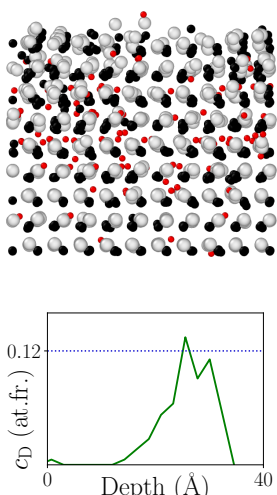

a $3 \operatorname{lag}^{\circ}$ (c) $10 \mathrm{eV}-500 \mathrm{~K}$

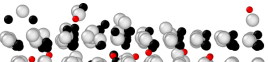
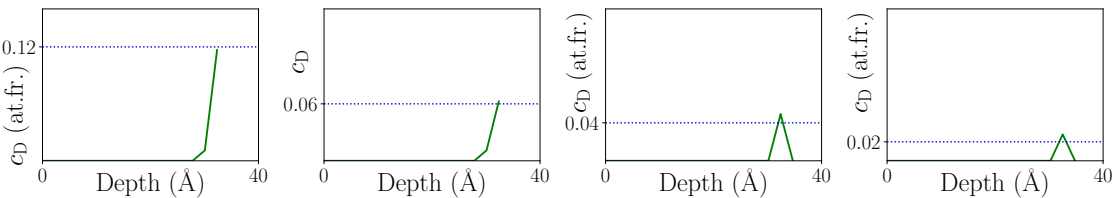

(d) $10 \mathrm{eV}-600 \mathrm{~K}$

(e) $10 \mathrm{eV}-700 \mathrm{~K}$

(f) $10 \mathrm{eV}-800 \mathrm{~K}$ .

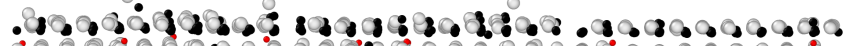
.0.0.0.0.0.0.0.0.0.0.0.0.0.0.0.0.0.0.0 - o.

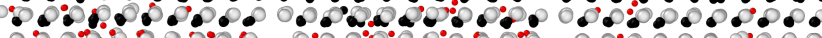

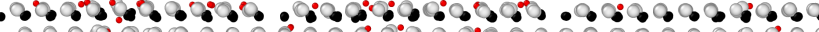

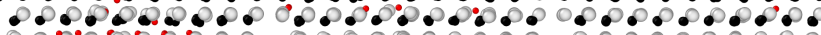

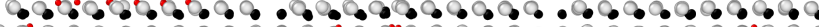

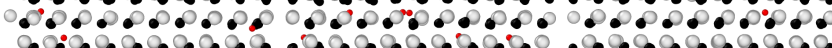

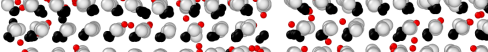
:.0.0.0.0.0.

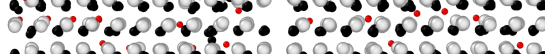

Depth $(\mathrm{A})$

(g) $50 \mathrm{eV}-300 \mathrm{~K}$
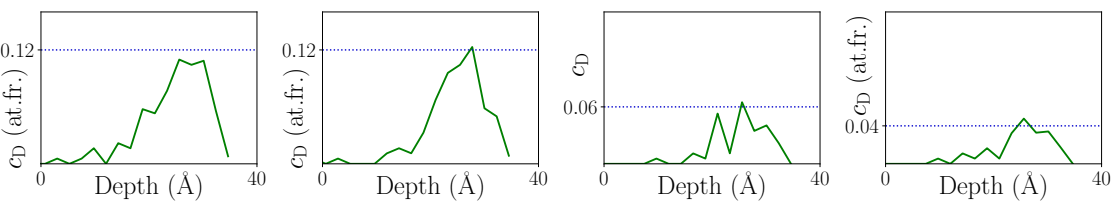

Depth $(\AA)$

(j) $50 \mathrm{eV}-600 \mathrm{~K}$

(k) $50 \mathrm{eV}-700 \mathrm{~K}$

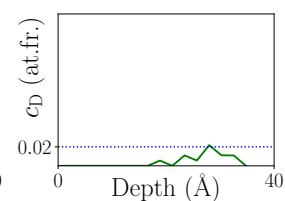

(i) $50 \mathrm{eV}-500 \mathrm{~K}$

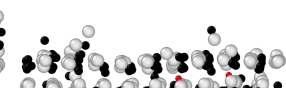

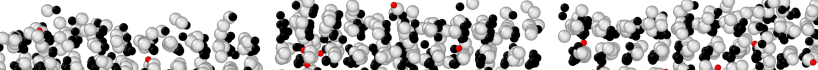
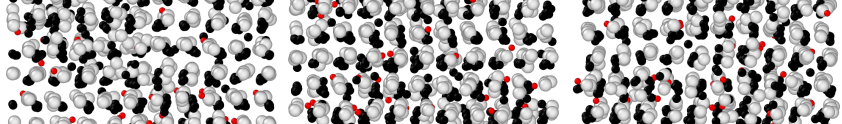

-.0.635.

20.030 .35

H. H.
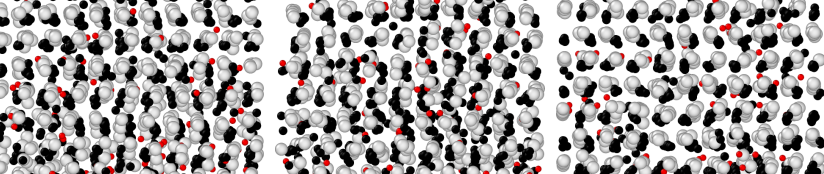

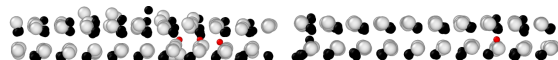
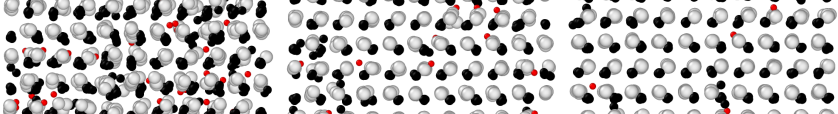

.0 .0 .0 .0 .0
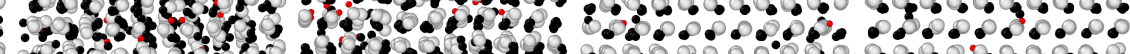

$\because 0_{0} \cdot 0 \cdot 0 \cdot 0 \cdot 0$
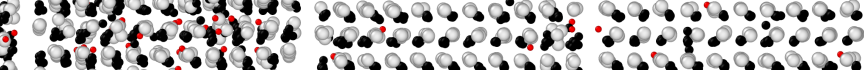

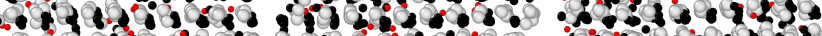

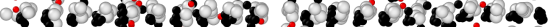

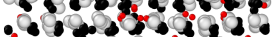
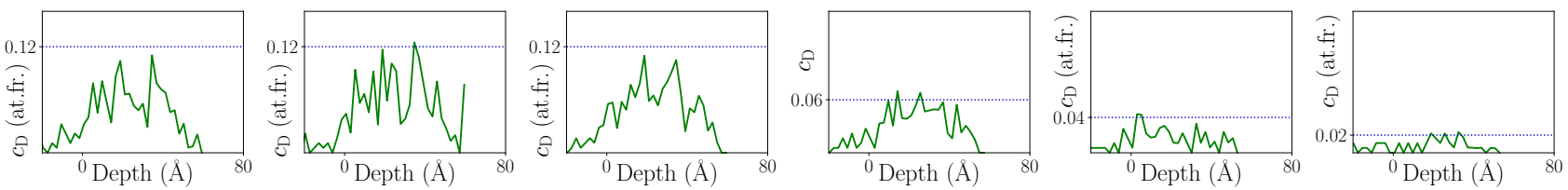

(m) $140 \mathrm{eV}-300 \mathrm{~K}$ (n) $140 \mathrm{eV}-400 \mathrm{~K}$ (o) $140 \mathrm{eV}-500 \mathrm{~K}$

(p) $140 \mathrm{eV}-600 \mathrm{~K}$

(q) $140 \mathrm{eV}-700 \mathrm{~K}$

(r) $140 \mathrm{eV}-800 \mathrm{~K}$

Figure 2: Simulation cells obtained by the cumulative irradiation and used for the non-cumulative irradiations for the different temperatures from $300 \mathrm{~K}$ to $800 \mathrm{~K}$ and incident energies of $10 \mathrm{eV}$ ((a) to (f)), $50 \mathrm{eV}$ ((g) to (l)) and $140 \mathrm{eV}((\mathrm{m})$ to $(\mathrm{r}))$. Top: Snapshot of the cells, obtained with the OVITO software [19, with O atoms in grey, Be in black and D in red. Bottom: Evolution of the deuterium concentration $c_{\mathrm{D}}$ in the depth for the considered cells. The experimental concentrations are shown with a dotted line.

been obtained with the exact same procedure. The cell is $25 \times 24 \AA^{2}$ in the $(\mathrm{x}, \mathrm{y})$ plane and is elongated in the $\mathrm{z}$ direction $\left(\mathrm{Z}=68 \AA\right.$ for $E_{\text {inc }}<80 \mathrm{eV}$ and $\mathrm{Z}=104$ $\AA$ for $\geq 80 \mathrm{eV}$ ). Each irradiation lasts for $7000 \mathrm{fs}$ and prior to any irradiation, the box is randomly shifted over the periodic boundaries in the $x$ and $y$ direction to simulate a uniform bombardment. More details on the simulation set-up (relaxation of the box, temperature control, incident angle) can be found in 8 .

As in 8, first, cumulative irradiations are run to build up a D-rich layer. The cumulative irradiations are stopped when the D concentration in this layer is 
comparable to the experimental ones. The values of $c_{\mathrm{D}}$ obtained during this first step are shown in figure 1 (averaged over the 6 energies). For the lowest temperatures, these concentrations are reached after about 100 (for $10 \mathrm{eV}$ ) or 400 (for $200 \mathrm{eV}$ ) impacts, while only few tens of impacts are needed for the highest temperatures (lowest $c_{\mathrm{D}}$ ). The cells obtained this way and used in the non-cumulative irradiation are shown in figure 2 for incident energies of $10 \mathrm{eV}, 50 \mathrm{eV}$ and $140 \mathrm{eV}$ for the different temperatures. For $30 \mathrm{eV}(80 \mathrm{eV})$, the cells are similar to the ones obtained for $50 \mathrm{eV}$ with more (less) D atoms on the surface. For $200 \mathrm{eV}$, the simulation cells are similar to the ones obtained for 140 $\mathrm{eV}$ with a more pronounced swelling of the cell for the highest value of $c_{\mathrm{D}}$. The $\mathrm{D}$ depth profiles are limited to the implantation zone (few nm below the surface) as the diffusion coefficient of $\mathrm{H}$ in $\mathrm{BeO}$ is large [20, 21] meaning that no diffusion can be captured at the MD time scale.

After building up the relevant deuterium concentration in the material, 10000 non-cumulative impacts are simulated to determine the sputtering yields of $\mathrm{BeO}, Y_{\mathrm{BeO}}$, calculated as the average number of sputtered $\mathrm{Be}$ and $\mathrm{O}$ atoms over incoming $\mathrm{D}$ ions. The standard deviation over all individual bombardments are used to provide error bars to the estimated sputtering yields. Again, to simulate a uniform bombardment, the simulation cell is randomly shifted over the periodic boundaries in the $\mathrm{x}$ and $\mathrm{y}$ direction before any impacts.

\section{Results and discussion}

\subsection{Evolution of $Y_{\mathrm{BeO}}$ with the temperature}

The sputtering yields calculated by MD calculations for the different incident energies and temperatures are reported in figure 3 and are correlated to the evolution of $c_{\mathrm{D}}$ with temperature. Experimental data at room temperature on oxidized Be samples [22, 24] and sintered $\mathrm{BeO}$ [23] are also reported. For all energies, $Y_{\mathrm{BeO}}$ increases from $300 \mathrm{~K}$ to $500 \mathrm{~K}$ as $c_{\mathrm{D}}$ is constant, and as soon as $c_{\mathrm{D}}$ decreases, $Y_{\mathrm{BeO}}$ decreases as well. Such peaking of the sputtering yield with temperature has already been reported for carbon-based materials [25, 26, 27] and Si 25] and is understood to be evidence of chemical sputtering [27. Concerning $\mathrm{BeO}$, the evolution of the sputtering yields with temperature has not been studied experimentally so far. However, concerning metallic Be, Nishijima et al 28] observed experimentally a decrease of the sputtering yield of plasma-deposited Be layer from $320 \mathrm{~K}$ to $570 \mathrm{~K}$ that they attributed to a decrease of the deuterium retention at $570 \mathrm{~K}$. In addition, the sputtering yield of $\mathrm{Be}$ in JET has also been shown to decrease from $200^{\circ} \mathrm{C}(473 \mathrm{~K})$ to $400^{\circ} \mathrm{C}(673$
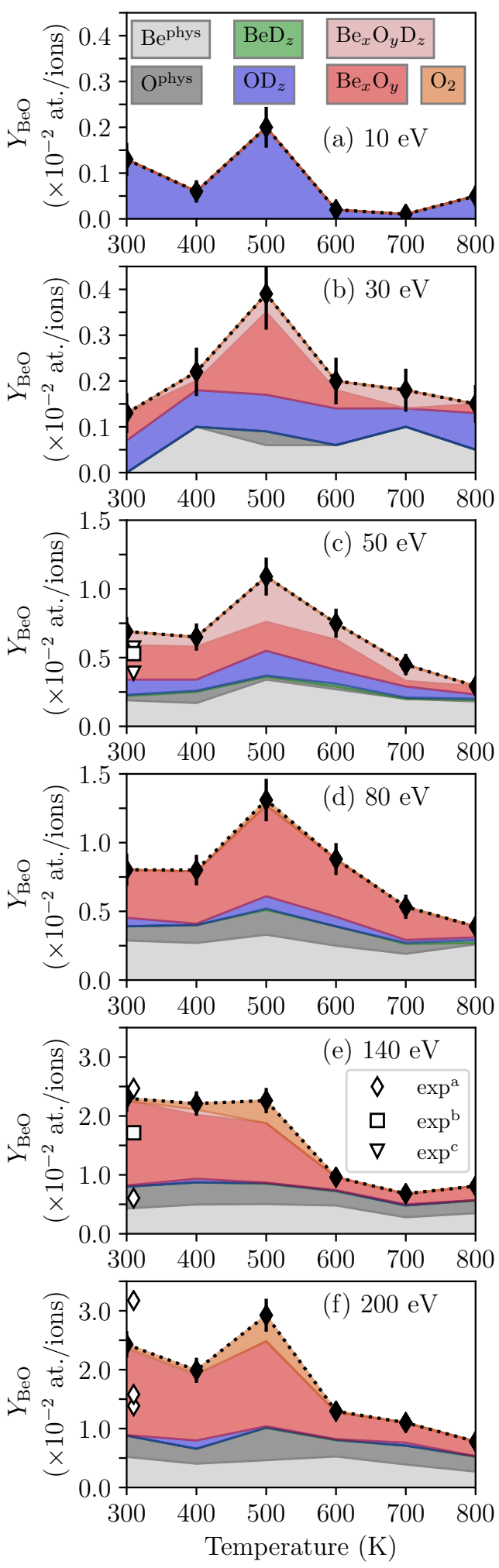

Figure 3: Evolution of the MD sputtering yield $Y_{\mathrm{BeO}}$ with the temperatures. The contributions of single Be atoms $\left(\mathrm{Be}^{\text {phys }}\right)$, single $\mathrm{O}$ atoms $\left(\mathrm{O}^{\text {phys }}\right), \mathrm{BeD}_{z}, \mathrm{OD}_{z}$, $\mathrm{Be}_{x} \mathrm{O}_{y}, \mathrm{Be}_{x} \mathrm{O}_{y} \mathrm{D}_{z}$ and $\mathrm{O}_{2}$ are also shown. exp ${ }^{\mathrm{a}}$ [22] $(150 \mathrm{eV}$ and $200 \mathrm{eV}), \exp ^{\mathrm{b}}$ [23] (50 eV and $\left.150 \mathrm{eV}\right)$ and $\exp ^{\mathrm{c}}$ 24] $(50 \mathrm{eV}$ and $60 \mathrm{eV})$ 
K) [29, 30. It is explained by the decrease of $c_{\mathrm{D}}$ in Be with temperature, diminishing the production of $\mathrm{BeD}$ molecules as shown in MD simulations [31. Thus, to investigate further the observed peaking of $Y_{\mathrm{BeO}}$ at $500 \mathrm{~K}$, we distinguished the different sputtering products as follows: single $\mathrm{O} / \mathrm{Be}$ atoms, $\mathrm{BeD}_{z}$ and $\mathrm{OD}_{z}$ molecules, $\mathrm{Be}_{x} \mathrm{O}_{y}, \mathrm{Be}_{x} \mathrm{O}_{y} \mathrm{D}_{z}$ and $\mathrm{O}_{2}$ molecules. For $\mathrm{OD}_{z}$ molecules, $\mathrm{z}$ is equal to 1 or 2 ( $\mathrm{z}=2$ is heavy water molecules). The contribution of each of these products is shown in figure 3 .

\subsection{Physical sputtering of $B e$ and $O$}

The single atoms are produced through physical sputtering processes and no strong temperature evolution can be determined for physical sputtering of $\mathrm{Be}$ and $\mathrm{O}$. One can still note that for $30 \mathrm{eV}$, there is no single Be sputtered at $300 \mathrm{~K}$ while there are at higher temperature. Regarding the obtained sputtering yields of $\approx 1 \times 10^{-3}$, this represents about 10 sputtering events among the 10000 non-cumulative irradiations. Thus, sputtering of few Be could have been missed by the limited number of impacts.

In figure 3, one can roughly estimate the threshold for physical sputtering of $\mathrm{Be}$ and $\mathrm{O}$. It is between 10 and $30 \mathrm{eV}$ for $\mathrm{Be}$ while it is around $30 \mathrm{eV}$ for $\mathrm{O}$. This difference makes sense considering the difference of mass between these two elements.

\subsection{Swift chemical sputtering of $O D_{z}$ molecules}

The $\mathrm{BeD}_{z}$ and $\mathrm{OD}_{z}$ molecules are mostly produced by swift chemical sputtering (SCS) [8, 32. The proportion of $\mathrm{BeD}_{z}$ is at maximum a few percent while the one of $\mathrm{OD}_{z}$ is $100 \%$ for $10 \mathrm{eV}$. The predominance of $\mathrm{OD}_{z}$ comes mostly from the fact that the OD dimer is much more stable than $\mathrm{BeD}[8$.

For $10 \mathrm{eV}$, this contribution, which represents all the sputtering events, peaks at $500 \mathrm{~K}$ and then drops by one order of magnitude as $c_{\mathrm{D}}$ decreases. In [8, we showed that the SCS mechanism is active for $10 \mathrm{eV}<$ $E_{\text {inc }} \leq 80 \mathrm{eV}$ for a perfect $(000 \overline{1})$ surface. However, the presence of adsorbed $\mathrm{D}$ leads to the formation of O-D bonds, which loosen the bond of the $\mathrm{O}$ atoms to the rest of the material [8]. Such a bound O atom can then be sputtered by $10 \mathrm{eV} \mathrm{D}$ ions. The amount of O-D bonds on the surface for the highest values of $c_{\mathrm{D}}(300$ $\mathrm{K}-500 \mathrm{~K}$ ) is obviously higher (figure 2 (a) to (c)) than for the lowest values of $c_{\mathrm{D}}(700 \mathrm{~K}-800 \mathrm{~K})$. For $700 \mathrm{~K}$ and $800 \mathrm{~K}$, no O-D bonds are actually on the surface and all the $\mathrm{D}$ atoms are below the surface (figure 2 (e), (f)).

For $E_{\text {inc }} \geq 30 \mathrm{eV}$, the temperature dependence of the formation of $\mathrm{OD}_{z}$ through SCS is not as obvious, except for a slight increase from $400 \mathrm{~K}$ to $500 \mathrm{~K}$ at $50 \mathrm{eV}$. Indeed, other sputtering processes start to appear (physical sputtering, formation of $\mathrm{Be}_{x} \mathrm{O}_{y} \mathrm{D}_{z}$ molecules). Thus, SCS leading to $\mathrm{OD}_{z}$ molecules contribute only to a few tens of percent at $30 \mathrm{eV}$, a few percent at $50 \mathrm{eV}$ and $80 \mathrm{eV}$ and almost 0 above that as the upper limit for this process is about 80 $\mathrm{eV}[8$.

\subsection{Sputtering of $\mathrm{Be}_{x} \mathrm{O}_{y} D_{z}$ molecules}

In the Be-O potentials used here, the energy of the $\mathrm{BeO}$ dimer had to be overestimated by $1 \mathrm{eV} /$ atom in order to have accurate cohesive energies for the bulk phases 15. This could favor the formation of $\mathrm{Be}_{x} \mathrm{O}_{y} \mathrm{D}_{z}$ molecules in our $\mathrm{MD}$ simulations that appear mostly as $\mathrm{BeO}$ dimer and $\mathrm{BeOD}$ molecules. However, $\mathrm{BeO}, \mathrm{BeOD}$ and $\mathrm{BeO}_{2}$ molecules have been observed experimentally by mass spectrometry after the bombardment of Be samples by an $\left(\mathrm{Ar}^{+}+\mathrm{D}_{2}^{+}\right)$ mixture 33. Thus, their formation in our MD simulations is not an artifact of the potential.

For $E_{\text {inc }} \geq 30 \mathrm{eV}$, as can be seen in figure 3 . the temperature dependence of $Y_{\mathrm{BeO}}$ is mostly due to the sputtering of $\mathrm{Be}_{x} \mathrm{O}_{y}\left(\mathrm{D}_{z}\right)$ molecules (including $\left.\mathrm{O}_{2}\right)$. For most of the events involving $\mathrm{Be}_{x} \mathrm{O}_{y}\left(\mathrm{D}_{z}\right)$ formation, the incident ion is not bound to the sputtered molecules: the initial interaction leading to the sputtering has a physical nature. It is the description of the chemically assisted physical sputtering (CAPS) suggested by Brezinsek et al 34. In our previous simulations of irradiations of $\mathrm{BeO}$ at $300 \mathrm{~K}$, we determined 4 processes leading to the production of these molecules via CAPS. First, there are two types of $\mathrm{BeO}$ physical sputtering mechanisms (direct and delayed) called $Y_{\mathrm{Be}_{x} \mathrm{O}_{y} \mathrm{D}_{z}}^{\text {phys }}$. During a direct physical sputtering event, the incident D ion physically sputters one $\mathrm{Be} / \mathrm{O}$ atom which drags with it one of its $\mathrm{O} / \mathrm{Be}$ neighbors forming a $\mathrm{BeO}$ dimer. During a delayed physical sputtering event, the incident $\mathrm{D}$ atom physically sputters one atom in its way in the material, is back-scattered and sputters another atom in its way back. If both sputtered atoms were neighbors, they might be sputtered together within a short space and time window allowing them to stay bound as a $\mathrm{BeO}$ dimer (this is a rare event due to the conditions required for it). Trajectories for both mechanisms can be found in 8. Then, there are two other processes active only on damaged surfaces, i.e. surfaces containing roughness and loosely bound groups of atoms (figure 2p. The first is the delayed SCS sputtering during which an atom is kicked away from its initial position. It can then move on the surface and possibly interact with other atoms via the SCS mechanism releasing a molecules. The second is the detachment induced sputtering: on the damaged surface, there are atoms or groups of atoms that are more loosely bound to the surface than any atoms on 
a pristine surface. If the incident $\mathrm{D}$ ion kicks off the atoms that bond a group of these atoms to the rest of the material, they can be detached from the surface. Trajectories for both mechanisms can also be found in [8]. Both processes are regrouped in $Y_{\mathrm{Be}_{x} \mathrm{O}_{y} \mathrm{D}_{z}}^{\mathrm{dam}}$.

For $c_{\mathrm{D}} \approx 0$ at.fr., with a perfect $(000 \overline{1})$ surface, among these two processes, only $Y_{\mathrm{Be}_{x} \mathrm{O}_{y} \mathrm{D}_{z}}^{\text {phys }}$ is active and it represents about 30 percent of the total sputtering yield [8. In figure 3, for $700 \mathrm{~K}$ and $800 \mathrm{~K}\left(c_{\mathrm{D}}<0.04\right.$ at.fr.), the contribution of $\mathrm{Be}_{x} \mathrm{O}_{y}\left(\mathrm{D}_{z}\right)$ is also about 30 percent and the irradiated surfaces are almost perfect (0001) (figure 2). Thus, at these temperatures, only $Y_{\mathrm{Be}_{x} \mathrm{O}_{y} \mathrm{D}_{z}}^{\mathrm{phys}}$ is active.

On the other hand, for the highest values of $c_{\mathrm{D}}$ $(300 \mathrm{~K}$ to $600 \mathrm{~K})$, as seen in figure 2, the material is more damaged (and eventually amorphized). This amorphization and surface damage are expected in insulator material [35]: the energy threshold for this amorphization can be very low (about $0.01 \mathrm{keV} /$ target atom) for material that are more covalent than ionic [35], which is the case of $\mathrm{BeO}$ [36]. Thus, it activates $Y_{\mathrm{Be}_{x} \mathrm{O}_{y} \mathrm{D}_{z}}^{\mathrm{dam}}$ for the highest values of $c_{\mathrm{D}}$ for which $Y_{\mathrm{Be}_{x} \mathrm{O}_{y} \mathrm{D}_{z}}$ contribute between 30 and 60/70 percent to the total sputtering yield. As a larger amount of irradiation is needed to build up the relevant value of $c_{\mathrm{D}}$, the surfaces for higher $c_{\mathrm{D}}$ are more damaged than for low $c_{\mathrm{D}}$. Thus, the decrease of $c_{\mathrm{D}}$ above $500 \mathrm{~K}$ induces a reduced amount of surface damage, leading to a decrease of $Y_{\mathrm{Be}_{x} \mathrm{O}_{y} \mathrm{D}_{z}}^{\mathrm{dam}}$ and hence also $Y_{\mathrm{BeO}}$ from $500 \mathrm{~K}$ to $800 \mathrm{~K}$.

Despite $c_{\mathrm{D}}(300 \mathrm{~K})>c_{\mathrm{D}}(600 \mathrm{~K})$, for $30 \mathrm{eV} \leq$ $E_{\text {inc }} \leq 80 \mathrm{eV}$, there is $Y_{\mathrm{BeO}}(600 \mathrm{~K})>Y_{\mathrm{BeO}}(300 \mathrm{~K})$, a pronounced increase of $Y_{\mathrm{BeO}}$ from $300 \mathrm{~K}$ to $500 \mathrm{~K}$ and a smooth decrease above $500 \mathrm{~K}$. It means a thermally activated process either (i) increases the amount of surface damage when building up $c_{\mathrm{D}}$ or (ii) facilitates the sputtering of atoms thanks to the thermal motion. Both can play a role in the temperature behavior of $Y_{\mathrm{BeO}}$ but one can expect that the enhancement of $Y_{\mathrm{BeO}}$ by a higher thermal motion would be similar for any incident energies. As the peaking is only observed for $E_{\text {inc }} \leq 80 \mathrm{eV}$, it is most likely that the peaking of $Y_{\mathrm{BeO}}$ is due to a increase of the surface damage with the temperature (for constant $c_{\mathrm{D}}$ ). Indeed, the depth profiles in figure 2 show that the $\mathrm{D}$ atoms are deposited much closer to the surface for $50 \mathrm{eV}$ : the damage are close to (and eventually on) the surface. At $140 \mathrm{eV}$, the D atoms are much deeper in the bulk: even though the damage induced by the irradiations increases from $300 \mathrm{~K}$ to $500 \mathrm{~K}$ they are moslty located in the bulk and do not affect that much the surface and the sputtering yield. Thus, for all energies, the disorder and damage induced by the ion irradiations increases with the temperature (from $300 \mathrm{~K}$ to $500 \mathrm{~K}$ ), but they affect the sputtering yield in that range of temperature only if they are close to the surface. This difference in deposition also leads to higher surface $\mathrm{D}$ concentrations at low energy, especially for $30 \mathrm{eV}$ and $50 \mathrm{eV}$, leading to a higher relative contribution of $\mathrm{Be}_{x} \mathrm{O}_{y} \mathrm{D}_{z}$ in the total sputtering yield.

Finally, one can note that $\mathrm{O}_{2}$ is only formed in high fraction at $500 \mathrm{~K}$ for $E_{\text {inc }} \geq 140 \mathrm{eV}$ (figure 3). For these energies, the morphology of the surface damage (figure $2 \mathrm{~m}-\mathrm{r}$ ) favor the delayed SCS sputtering. $\mathrm{O}_{2}$ can then be formed if an $\mathrm{O}$ atom migrating on the surface recombines with another one. The surface damage for $E_{\text {inc }} \geq 140 \mathrm{eV}$ can also lead to the formation of adsorbed $\mathrm{O}_{2}$ molecules as two $\mathrm{O}$ atoms are close together (one of their common Be neighbor being sputtered away during the cumulative irradiation). These $\mathrm{O}_{2}$ molecules can be outgassed by the local increase of temperature created by the incident $\mathrm{D}$ ion impact. As the surface disorders are the highest at $500 \mathrm{~K}$ and as outgassing is also favored by higher temperature, this explains the high fraction of $\mathrm{O}_{2}$ production at $500 \mathrm{~K}$.

\section{Conclusions}

MD simulations of the irradiation of (0001) wurtzite $\mathrm{BeO}$ surface at energies from $10 \mathrm{eV}$ to $200 \mathrm{eV}$ and temperatures from $300 \mathrm{~K}$ to $800 \mathrm{~K}$ have been carried out to estimate the variation of the $\mathrm{BeO}$ sputtering yield $Y_{\mathrm{BeO}}$ with temperature. First, cumulative irradiations were done to build a concentration of deuterium, $c_{\mathrm{D}}$ in the material. From experimental results, the value of $c_{\mathrm{D}}$ depends on the irradiation temperature [17, 18]: it is 0.12 at.fr. from $300 \mathrm{~K}$ to $500 \mathrm{~K}$ and it drops up to 0.02 at.fr. at $800 \mathrm{~K}$. In the simulations, for all energies, $Y_{\mathrm{BeO}}$ follows the trends of $c_{\mathrm{D}}(T)$ above $500 \mathrm{~K}$ : it decreases as the concentration of deuterium decreases. In the temperature range where $c_{\mathrm{D}}$ is constant equal to 0.12 at.fr. $(300 \mathrm{~K}-500 \mathrm{~K}), Y_{\mathrm{BeO}}$ increases. For $10 \mathrm{eV}$, only $\mathrm{OD}_{z}$ molecules are sputtered and the decrease of $Y_{\mathrm{BeO}}$ with temperature $/ c_{\mathrm{D}}$ is due to a decrease of the amount of O-D bonds on the surface as these bonds decrease the binding energy of the $\mathrm{O}$ atom to the rest of the material. Above $30 \mathrm{eV}$, the variation of $Y_{\mathrm{BeO}}$ with temperature is mainly due to the evolution of the sputtering of $\mathrm{Be}_{x} \mathrm{O}_{y} \mathrm{D}_{z}$ molecules due to the change in surface damage: as $c_{\mathrm{D}}$ decreases, the amount of surface damage decreases as well as $Y_{\mathrm{BeO}}$.

\section{Acknowledgments}

The work was perfomed under EUROfusion WP PFC. This work has been carried out within the framework of the EUROfusion Consortium and has received funding from the Euratom research and training programme 2014-2018 and 2019-2020 under grant agreement No 
633053. The views and opinions expressed herein do not necessarily reflect those of the European Commission. Grants of computer capacity from CSCIT Center for Science and the Finnish Grid and Cloud Infrastructure (persistent identifier urn:nbn:fi:researchinfras-2016072533) are gratefully acknowledged.

\section{References}

[1] V. Philipps, Ph. Mertens, G.F. Matthews, and H. Maier. Overview of the jet iter-like wall project. Fusion Engineering and Design, 85(7):1581 - 1586, 2010. Proceedings of the Ninth International Symposium on Fusion Nuclear Technology.

[2] S. Brezinsek. Plasma-surface interaction in the be/w environment: Conclusions drawn from the jet-ilw for iter. Journal of Nuclear Materials, 463:11 - 21, 2015. PLASMA-SURFACE INTERACTIONS 21.

[3] A. Loarte, B. Lipschultz, A.S. Kukushkin, G.F. Matthews, P.C. Stangeby, N. Asakura, G.F. Counsell, G. Federici, A. Kallenbach, K. Krieger, A. Mahdavi, V. Philipps, D. Reiter, J. Roth, J. Strachan, D. Whyte, R. Doerner, T. Eich, W. Fundamenski, A. Herrmann, M. Fenstermacher, P. Ghendrih, M. Groth, A. Kirschner, S. Konoshima, B. LaBombard, P. Lang, A.W. Leonard, P. Monier-Garbet, R. Neu, H. Pacher, B. Pegourie, R.A. Pitts, S. Takamura, J. Terry, E. Tsitrone, the ITPA Scrape-off Layer, and Divertor Physics Topical Group. Chapter 4: Power and particle control. Nuclear Fusion, 47(6):S203, 2007.

[4] S. Brezinsek, T. Loarer, V. Philipps, H.G. Esser, S. Grünhagen, R. Smith, R. Felton, J. Banks, P. Belo, A. Boboc, J. Bucalossi, M. Clever, J.W. Coenen, I. Coffey, S. Devaux, D. Douai, M. Freisinger, D. Frigione, M. Groth, A. Huber, J. Hobirk, S. Jachmich, S. Knipe, K. Krieger, U. Kruezi, S. Marsen, G.F. Matthews, A.G. Meigs, F. Nave, I. Nunes, R. Neu, J. Roth, M.F. Stamp, S. Vartanian, U. Samm, and JET EFDA contributors. Fuel retention studies with the iter-like wall in jet. Nuclear Fusion, 53(8):083023, 2013.

[5] K. Heinola, A. Widdowson, J. Likonen, E. Alves, A. BaronWiechec, N. Barradas, S. Brezinsek, N. Catarino, P. Coad, S. Koivuranta, G.F. Matthews, M. Mayer, and P. Petersson. Fuel retention in jet iter-like wall from post-mortem analysis. Journal of Nuclear Materials, 463:961 - 965, 2015. PLASMA-SURFACE INTERACTIONS 21.

[6] M. Kumar, C. Makepeace, C. Pardanaud, Y. Ferro, E. Hodille, C. Martin, P. Roubin, A. Widdowson, T. Dittmar, C.h. Linsmeier, C.P. Lungu, C. Porosnicu, I. Jepu, P. Dinca, M. Lungu, O.G. Pompilian, and JET contributors. Identification of beo and beoxdy in melted zones of the jet be limiter tiles: Raman study using comparison with laboratory samples. Nuclear Materials and Energy, 17:295 - 301, 2018.

[7] Makepeace C., Pardanaud C., Roubin P., Borodkina I., Ayres C., Coad P., Baron-Wiechec A., Jepu I., Heinola K., Widdowson A., Lozano-Perez S., and J.E.T. Contributors. The effect of beryllium oxide on retention in JET ITER-like wall tiles. Nuclear Materials and Energy, 19:346351, 2019.

[8] E A Hodille, J Byggmästar, E Safi, and K Nordlund. Molecular dynamics simulation of beryllium oxide irradiated by deuterium ions: sputtering and reflection. Journal of Physics: Condensed Matter, 31(18):185001, mar 2019.

[9] K. Nordlund, M. Ghaly, R. S. Averback, M. Caturla, T. Diaz de la Rubia, and J. Tarus. Defect production in collision cascades in elemental semiconductors and fcc metals. Phys. Rev. B, 57:7556-7570, Apr 1998.

[10] J. Tersoff. New empirical model for the structural properties of silicon. Phys. Rev. Lett., 56:632-635, Feb 1986.

[11] J. Tersoff. New empirical approach for the structure and energy of covalent systems. Phys. Rev. B, 37:6991-7000, Apr 1988.

[12] C. Björkas, N. Juslin, H. Timko, K. Vörtler, K. Nordlund, K. Henriksson, and P. Erhart. Interatomic potentials for the Be-C-H system. Journal of Physics: Condensed Matter, 21(44):445002, 2009.

[13] Donald W. Brenner. Empirical potential for hydrocarbons for use in simulating the chemical vapor deposition of diamond films. Phys. Rev. B, 42:9458-9471, Nov 1990.

[14] Paul Erhart, Niklas Juslin, Oliver Goy, Kai Nordlund, Ralf Müller, and Karsten Albe. Analytic bond-order potential for atomistic simulations of zinc oxide. Journal of Physics: Condensed Matter, 18(29):6585, July 2006.

[15] J Byggmästar, E A Hodille, Y Ferro, and K Nordlund. Analytical bond order potential for simulations of $\mathrm{BeO} 1 \mathrm{D}$ and 2D nanostructures and plasma-surface interactions. Journal of Physics: Condensed Matter, 30(13):135001, 2018.

[16] J. Roth, R. Doerner, M. Baldwin, T. Dittmar, H. Xu, K. Sugiyama, M. Reinelt, Ch. Linsmeier, and M. Oberkofler. Oxidation of beryllium and exposure of beryllium oxide to deuterium plasmas in PISCES B. Journal of Nuclear Materials, 438:S1044S1047, 2013. Proceedings of the 20th International Conference on Plasma-Surface Interactions in Controlled Fusion Devices.

[17] J. Roth, W.R. Wampler, M. Oberkofler, S. van Deusen, and S. Elgeti. Deuterium retention and out-gassing from beryllium oxide on beryllium. Journal of Nuclear Materials, 453(1):27 - 30, 2014.

[18] V. Kh. Alimov and A. P. Zakharov. Deuterium Retention In Beryllium and Beryllium Oxide, pages 247-264. Springer Netherlands, Dordrecht, 2000.

[19] Alexander Stukowski. Visualization and analysis of atomistic simulation data with ovitothe open visualization tool. Modelling and Simulation in Materials Science and Engineering, 18(1):015012, 2010.

[20] Etienne A Hodille, Yves Ferro, Zachary Piazza, and Cédric Pardanaud. Hydrogen in beryllium oxide investigated by DFT: on the relative stability of charged-state atomic versus molecular hydrogen. Journal of Physics: Condensed Matter, 2018.

[21] J. D. Fowler, Chandra Dipankar, T. S. Elleman, A. W. Payne, and Kuruvilla Verghese. Tritium Diffusion in A12O3 and BeO. Journal of the American Ceramic Society, 60(34):155161, 1977.

[22] Y. Hirooka, J. Won, R. Boivin, D. Sze, and V. Neumoin. Effect of impurities on the erosion behavior of beryllium under steady-state deuterium plasma bombardment. Journal of Nuclear Materials, 228(1):148153, 1996.

[23] J. Roth, J. Bohdansky, R.S. Blewer, W. Ottenberger, and J. Borders. Sputtering of $\mathrm{Be}$ and $\mathrm{BeO}$ by light ions. Journal of Nuclear Materials, 85-86:10771079, 1979.

[24] J. Roth, W. Eckstein, and J. Bohdansky. Beryllium selfsputtering: An interpolation of data for D, He, Ne and Ar. Journal of Nuclear Materials, 165(3):199204, 1989.

[25] M Balden and J Roth. Comparison of the chemical erosion of si, c and sic under deuterium ion bombardment. Journal of Nuclear Materials, 279(2):351 - 355, 2000.

[26] M. Schlüter, C. Hopf, T. Schwarz-Selinger, and W. Jacob. Temperature dependence of the chemical sputtering of amorphous hydrogenated carbon films by hydrogen. Journal of Nuclear Materials, 376(1):33 - 37, 2008.

[27] E. Salonen, K. Nordlund, J. Keinonen, and C. H. Wu. Swift 
chemical sputtering of amorphous hydrogenated carbon. Phys. Rev. B, 63:195415, Apr 2001.

[28] D. Nishijima, R.P. Doerner, M.J. Baldwin, and G. De Temmerman. Erosion yields of deposited beryllium layers. Journal of Nuclear Materials, 390-391:132 - 135, 2009. Proceedings of the 18th International Conference on Plasma-Surface Interactions in Controlled Fusion Device.

[29] S. Brezinsek, M.F. Stamp, D. Nishijima, D. Borodin, S. Devaux, K. Krieger, S. Marsen, M. O'Mullane, C. Björkas, A. Kirschner, and JET EFDA contributors. Study of physical and chemical assisted physical sputtering of beryllium in the jet iter-like wall. Nuclear Fusion, 54(10):103001, 2014.

[30] S. Brezinsek, A. Widdowson, M. Mayer, V. Philipps, P. Baron-Wiechec, J.W. Coenen, K. Heinola, A. Huber, J. Likonen, P. Petersson, M. Rubel, M.F. Stamp, D. Borodin, J.P. Coad, A.G. Carrasco, A. Kirschner, S. Krat, K. Krieger, B. Lipschultz, Ch. Linsmeier, G.F. Matthews, and K. Schmid and. Beryllium migration in JET ITER-like wall plasmas. Nuclear Fusion, 55(6):063021, may 2015.

[31] E Safi, G Valles, A Lasa, and K Nordlund. Multiscale modelling to relate beryllium surface temperature, deuterium concentration and erosion in fusion reactor environment. Journal of Physics D: Applied Physics, 50(20):204003, 2017.

[32] C Björkas, D Borodin, A Kirschner, R K Janev, D Nishijima, R Doerner, and K Nordlund. Molecules can be sputtered also from pure metals: sputtering of beryllium hydride by fusion plasmawall interactions. Plasma Physics and Controlled Fusion, 55(7):074004, 2013.

[33] Kan Ashida, Masao Matsuyama, Kuniaki Watanabe, Hiroshi Kawamura, and Etsuo Ishitsuka. Secondary ion emission from beryllium surfaces by ar and /or ( $\operatorname{ar}+\mathrm{d} 2)$ mixed ion bombardments. Journal of Nuclear Materials, 210(3):233 - 238, 1994.

[34] S. Brezinsek, A. Pospieszczyk, G. Sergienko, R. Dux, M. Cavedon, M. Faitsch, and K. Krieger. Chemically assisted physical sputtering of tungsten: Identification via the $66+$ transition of wd in textor and asdex upgrade plasmas. Nuclear Materials and Energy, 18:50 - 55, 2019.

[35] Linn W. Hobbs. Topology and geometry in the irradiation-induced amorphization of insulators. Nuclear Instruments and Methods in Physics Research Section B: Beam Interactions with Materials and Atoms, 91(1):30 - 42, 1994.

[36] A. Allouche and Y. Ferro. First-Principles Study of hydrogen retention and diffusion in beryllium oxide. Solid State Ionics, 272:91100, 2015. 